\title{
Practical approach to respiratory emergencies in neurological diseases
}

\author{
Fabrizio Racca ${ }^{1} \cdot$ Andrea Vianello $^{2} \cdot$ Tiziana Mongini $^{3} \cdot$ Paolo Ruggeri $^{4} \cdot$ Antonio Versaci $^{5} \cdot$ Gian Luca Vita $^{6}$. \\ Giuseppe Vita ${ }^{6,7}$
}

Received: 1 October 2019 / Accepted: 15 November 2019 / Published online: 2 December 2019

(C) Fondazione Società Italiana di Neurologia 2019

\begin{abstract}
Many neurological diseases may cause acute respiratory failure (ARF) due to involvement of bulbar respiratory center, spinal cord, motoneurons, peripheral nerves, neuromuscular junction, or skeletal muscles. In this context, respiratory emergencies are often a challenge at home, in a neurology ward, or even in an intensive care unit, influencing morbidity and mortality. More commonly, patients develop primarily ventilatory impairment causing hypercapnia. Moreover, inadequate bulbar and expiratory muscle function may cause retained secretions, frequently complicated by pneumonia, atelectasis, and, ultimately, hypoxemic ARF. On the basis of the clinical onset, two main categories of ARF can be identified: (i) acute exacerbation of chronic respiratory failure, which is common in slowly progressive neurological diseases, such as movement disorders and most neuromuscular diseases, and (ii) sudden-onset respiratory failure which may develop in rapidly progressive neurological disorders including stroke, convulsive status epilepticus, traumatic brain injury, spinal cord injury, phrenic neuropathy, myasthenia gravis, and Guillain-Barré syndrome. A tailored assistance may include manual and mechanical cough assistance, noninvasive ventilation, endotracheal intubation, invasive mechanical ventilation, or tracheotomy. This review provides practical recommendations for prevention, recognition, management, and treatment of respiratory emergencies in neurological diseases, mostly in teenagers and adults, according to type and severity of baseline disease.
\end{abstract}

Keywords Neurological diseases · Respiratory failure - Hypercapnia · Hypoxemia - Invasive mechanical ventilation · Noninvasive ventilation

Fabrizio Racca and Andrea Vianello contributed equally to this work.

Giuseppe Vita

vitag@unime.it

1 Department of Anaesthesia and Intensive Care, Sant'Antonio e Biagio e Cesare Arrigo Hospital, Alessandria, Italy

2 Respiratory Pathophysiology Division, University of Padua, Padua, Italy

3 Neuromuscular Center, Department of Neurosciences, University of Turin, Turin, Italy

4 Unit of Pneumology, Department BIOMORF, University of Messina, Messina, Italy

5 Intensive Care Unit, AOU Policlinico "G. Martino", Messina, Italy

6 Nemo Sud Clinical Centre for Neuromuscular Disorders, Messina, Italy

7 Unit of Neurology and Neuromuscular Diseases, Department of Clinical and Experimental Medicine, University of Messina, Messina, Italy

$\begin{array}{ll}\text { Abbreviations } \\ \text { ALS } & \text { Amyotrophic lateral sclerosis } \\ \text { ARDS } & \text { Acute respiratory distress syndrome } \\ \text { ARF } & \text { Acute respiratory failure } \\ \text { AT } & \text { Ataxia telangiectasia } \\ \text { CNS } & \text { Central nervous system } \\ \text { CPEF } & \text { Cough peak expiratory flow } \\ \text { DM } & \text { Dermatomyositis } \\ \text { DM1 } & \text { Myotonic dystrophy type 1 } \\ \text { DMD } & \text { Duchenne muscular dystrophy } \\ \text { ER } & \text { Emergency room } \\ \text { ETI } & \text { Endotracheal intubation } \\ \text { FSHD } & \text { Facioscapulohumeral muscular dystrophy } \\ \text { FVC } & \text { Forced vital capacity } \\ \text { GBS } & \text { Guillain-Barré syndrome } \\ \text { GCS } & \text { Glasgow coma scale } \\ \text { ICU } & \text { Intensive care unit } \\ \text { IMV } & \text { Invasive mechanical ventilation } \\ \text { IOPD } & \text { Infantile-onset Pompe disease }\end{array}$

\section{Abbreviations}

ARDS Acute respiratory distress syndrome

AT

Ataxia telangiectasia

Central nervous system

Dermatomyositis

DM1

Duchenne muscular dystrophy

ER

Endotracheal intubation

FVC

Forced vital capacity

GBS

endrome

GCS

Intensive care unit

IOPD 


$\begin{array}{ll}\text { MG } & \text { Myasthenia gravis } \\ \text { MIP } & \text { Maximum inspiratory pressure } \\ \text { NIV } & \text { Noninvasive ventilation } \\ \text { NMDs } & \text { Neuromuscular disorders } \\ \text { PD } & \text { Parkinson's disease } \\ \text { PM } & \text { Polymyositis } \\ \text { RF } & \text { Respiratory failure } \\ \text { SCI } & \text { Spinal cord injury } \\ \text { SE } & \text { Status epilepticus } \\ \text { SMA } & \text { Spinal muscular atrophy } \\ \text { TBI } & \text { Traumatic brain injury } \\ \text { UAO } & \text { Upper airway obstruction }\end{array}$

\section{Introduction}

Severe cerebrovascular diseases, traumatic injuries of brain and spinal cord, and other toxic, dysmetabolic, infectious, inflammatory, or degenerative diseases involving the central nervous system (CNS) can trigger hypoxic and/or hypercapnic respiratory failure (RF) directly or through major pulmonary complications such as pneumonia, pulmonary edema, and traumatic pneumothorax [1]. Acute respiratory failure (ARF) may often occur in patients with acute or chronic neuromuscular diseases (NMDs) such as Guillain-Barré syndrome (GBS), amyotrophic lateral sclerosis (ALS), myasthenia gravis (MG), spinal muscular atrophy (SMA), Duchenne muscular dystrophy (DMD), polymyositis (PM), or dermatomyositis (DM). In these patients, weakness of diaphragm, intercostal and expiratory muscles, or concomitant pulmonary complications due to oropharyngeal dysfunction causing aspiration of secretions/food/drink or inefficient cough may lead to respiratory emergencies [2]. In all these neurological disorders, respiratory involvement may increase the burden of the existing disease and mortality.

Respiratory emergencies in neurological diseases may occur at onset or more often along the chronic course of the disease. Emergency room (ER) physicians and consultant neurologists must be aware of the respiratory risks of such patients, be able to recognize early signs, and take action to treat RF adequately. In this context, a competent multidisciplinary team is fundamental including pneumologist, anesthetist, nurse, physical therapist, and speech therapist. Indeed, these cases not infrequently represent a diagnostic challenge in the acute care settings, especially in a busy ER, because of patients' poor ability to communicate and scanty experience of health professionals in caring for patients with neurological diseases [3, 4]. Furthermore, increase in survival of patients with SMA and DMD has emphasized the need for a smooth and successful transition from pediatric to adult healthcare [5, 6]. Unfortunately, many healthcare services are not equipped to provide modified age-appropriate assistance and expertise. This is particularly true at ER, leading to an inadequate medical approach and patients' and caregivers' apprehensiveness with loss of the sense of health protection $[7,8]$.

This review aims to update and provide practical recommendations to the professionals in emergency medical services for recognition, management, and treatment of respiratory emergencies in neurological diseases mostly occurring in teenagers and adults. Some preventive measures are also reported to decrease morbidity and mortality.

\section{Pathophysiology of respiratory failure}

$\mathrm{RF}$ is a syndrome in which the respiratory system fails in one or both of its gas exchange functions: oxygenation and carbon dioxide $\left(\mathrm{CO}_{2}\right)$ elimination. In practice, patients with RF can be categorized as those with primarily impairment of gas exchange due to intrinsic lung/airways disease, leading to hypoxemic RF ("lung failure"), and those with lung ventilation impairment on the basis of ventilatory pump disorders, leading to hypercapnic RF ("pump failure"). Patients with neurological disease more commonly develop primarily ventilatory impairment causing $\mathrm{CO}_{2}$ retention, although the probability of occurrence can be different, depending on baseline disease.

Respiratory muscle weakness, defined as the inability of the rested respiratory muscles to generate normal levels of pressure and flow during inspiration and expiration, is a common occurrence in patients with neuropathies or myopathies and provides the condition for the development of acute ventilatory failure [9]. As chest wall and pulmonary compliance may be reduced, mechanical load on weakened respiratory muscles (in particular the diaphragm) can be increased. An imbalance between load and capacity leads to muscle fatigue, which in turn elicits an increase in minute ventilation and respiratory rate and, to a lesser degree, a reduction in tidal volume ("rapid shallow breathing"), causing hypoventilation and ARF $[10,11]$.

Respiratory muscle weakness is frequently undetected in patients with neurological disease until ventilatory failure is precipitated by aspiration pneumonia or respiratory tract infection [12]. At onset, ventilatory insufficiency leading to failure may only be nocturnal and results from diaphragm failure, with the patient unable to breathe when supine, or from severe generalized respiratory muscle dysfunction. Due to the inadequacy of inspiratory muscle function, a well-known pattern of restrictive ventilatory defect can be detected by pulmonary function tests, with reduced forced vital capacity (FVC).

Effective cough requires deep inspiration followed by glottis closure and appropriate expiratory muscle strength to generate sufficient intrathoracic pressure and obtain high expiratory flows. Clearing airway secretions and airway mucus can be a continual problem for patients with generalized muscle weakness and for those who cannot swallow saliva or food without aspiration. Indeed, in patients with neurological 
disorders, inadequate bulbar and expiratory muscle function may cause retained secretions, frequently complicated by pneumonia, atelectasis, and, ultimately, hypoxemic ARF. These conditions can result in hospitalizations, endotracheal intubations, tracheostomy, and death [13]. In rapidly progressing NMDs, ARF due to accumulation of lung secretions ("lung failure") can be the earliest symptom [14]. Cough peak expiratory flow (CPEF) is a measure of the maximum airflow generated during cough and is normally 360 to $1200 \mathrm{~L}$ / min; of interest, CPEF may provide valuable information on the ability to clear airway secretions, with values below $160 \mathrm{~L} /$ min usually indicating the need for tracheal suctioning and an increased risk of mucous encumbrance at the onset of respiratory infections, contributing to the development of atelectasis and acute hypoxemia [15].

In conditions such as severe brain injury due to stroke or trauma, spinal cord injury, multiple sclerosis, tetanus, botulism and GBS, autonomic nervous system dysfunction may contribute to respiratory complications. They may be the effect of a reduction of airways vagal tone, a decreased bronchodilator effect of anticholinergic drugs, and a diminished ventilatory response to hypoxia and hypercapnia probably caused by dysfunction of aortic and carotid sinus mechanoreceptor transmission [16].

\section{Neurological diseases and acute respiratory involvement}

\section{Stroke}

After a stroke, the loss of ability to generate normal amounts of force is a major contributor to activity limitation and participation restriction. Weakness after stroke also affects muscles of the respiratory system, and patients typically have altered breathing control, reduced maximal voluntary strength, and decreased endurance of inspiratory and expiratory muscles, as well as altered chest wall kinematics $[17,18]$. Associated factors may be impaired vigilance, inefficient cough, aspiration, acute lung injury/acute respiratory distress syndrome (ARDS), pulmonary embolus, and pulmonary edema (neurogenic or cardiogenic) [19]. The risk of respiratory impairment associated to large hemispheric stroke increases after a few days' delay, as cerebral edema intensifies. Sustained hyperventilation in a patient with mass effect can be a manifestation of diencephalic herniation. Ataxic or cluster breathing patterns can be part of brainstem syndromes, and recurrent apnea is a warning sign in patients with basilar artery occlusion. Cheyne-Stokes breathing, characterized by oscillating cycles of hyperpnea alternating with periods of apnea, is a frequent finding after massive hemispheric stroke [20]. Chest infections, such as pneumonia, are the most frequent complications of stroke and occur in up to one-third of patients, resulting in up to a threefold increased risk of death in the first 30 days, longer hospital stay, and poorer postdischarge outcomes [21].

\section{Convulsive status epilepticus}

Status epilepticus (SE) is a neurological emergency with high morbidity and mortality requiring neurointensive care and treatment of systemic complications. The estimated annual incidence of SE varies according to studies, with values ranging between 9.9 and 41/100,000 inhabitants. ARF is a frequent complication (about $80 \%$ ) [22]. It is caused not only by the disease itself but also by the drugs used to treat SE. Aspiration pneumonia is frequent as airway protective reflexes decrease. Another possible respiratory complication is neurogenic pulmonary edema [23].

\section{Traumatic brain injury}

Traumatic brain injury (TBI) represents a leading cause of death and disability in adults, thus engaging considerable resources in the health system. ARF is frequent mainly because of airway protective reflex decrease, impaired cough, and altered breathing control. All these factors are related to the severity of consciousness reduction. The incidence of ARF associated with TBI has decreased over the last decade due to improvements in extra- and intrahospital management. However, it still remains one of the main causes of morbidity and mortality, and the incidence of residual respiratory failure at the end of acute hospitalization is approximately $32 \%[24$, 25].

\section{Spinal cord injury}

Respiratory complications are the foremost causes of increased morbidity and mortality after spinal cord injury (SCI), with an incidence of $36 \%$ to $83 \%$. The pathophysiology is complex, with the level and completeness of phrenic nucleus injury at $\mathrm{C} 3-\mathrm{C} 5$ level with diaphragm paralysis being the greatest determinant. Full cervical lesions $(\mathrm{C} 2-\mathrm{C} 4)$ in the absence of mechanical ventilation are incompatible with life. Cervical lesions under C5 (C5-C8) determine weakness or paralysis only of the intercostal and abdominal muscles. In these cases, the diaphragm is preserved, and spontaneous ventilation is usually maintained. Other responsible factors are accessory muscle weakness due to T1-T12 level injury and abdominal muscle involvement due to T5-T12 injury, impaired cough, decreased surfactant production, and increased secretions and bronchospasm due to unopposed vagal activity (C8-L2 sympathetic nerve injury) [26].

Patients may rapidly deteriorate with the need for urgent intubation [27]. In a large prospective study, $67 \%$ of 261 acutely injured subjects experienced severe respiratory 
complications. Atelectasis (36.4\%), pneumonia (31.4\%), and ventilatory failure $(22.6 \%)$ were the most common complications. Ventilatory failure and impaired cough are the main causes of RF. Other responsible factors are pulmonary edema and pneumohemothorax. Ventilatory failure lasted an average of 5 weeks [28]. Transfer to an SCI center specializing in acute management of tetraplegia may significantly reduce the number of respiratory complications.

\section{Inflammatory and infectious diseases of the CNS}

Inflammatory and infectious diseases of the CNS are a very heterogeneous group of diseases that can affect CNS function with different patterns of symptoms and signs. Pulmonary complications are related to an altered breathing control system, severity of associated reduction of consciousness, and involvement of respiratory muscles. Pulmonary impairments have long been recognized as major causes of morbidity and mortality in individuals with advanced multiple sclerosis, due to acute or chronic respiratory disorders. Chronic RF involves bulbar dysfunction with swallowing disorders, altered central respiratory drive, motor disorders following corticospinal lesions, or sleep-disordered breathing. Acute conditions mainly involve spinal or bulbar relapse with extensive plaques, neurogenic pulmonary edema, or ARF, often following sepsis [29]. Common pulmonary-related complications in encephalitis are poor gag reflex, pooling of secretion, and loss of swallowing, with risk of aspiration pneumonia and RF development [30].

\section{Parkinson's disease}

Rigidity and hypokinesia of both the upper airway and the chest wall are thought to contribute to upper airway obstruction (UAO) in patients with Parkinson's disease (PD). Restrictive changes are also a common functional abnormality, due to loss of chest wall compliance secondary to severe rigidity [31]. A reduced ventilatory response to hypoxia and hypercapnia related to low ventilatory chemosensitivity and autonomic dysfunction may contribute to the development of ARF [32]. Swallowing impairment exposes PD patients to high risk of aspiration pneumonia that is enhanced by weak cough due to chest wall rigidity, dyskinesia, and upper airway dysfunction. Pneumonia remains the most common frequent cause of death despite the development of effective therapeutic regimen over the past three decades [33]. Although levodopa is the main treatment for PD, improving respiratory and motor functions, development of dyskinesias may affect ventilation inducing dyspnea and chest pain. Moreover, in advanced patients, wearing-off phenomenon may induce pulmonary complaints such as stridor due to UAO and dyspnea due to chest wall tightness.

\section{Ataxias}

Subclinical restrictive type of pulmonary dysfunction is present in spinocerebellar ataxias with possible UAO [34]. Particularly in ataxia telangiectasia (AT), respiratory complications may account for $1 / 3$ of deaths. Secondary effects of AT on the lung are related to suboptimal muscle strength due to coordination problem, impaired airway clearance due to weak cough, and abnormal swallow and aspiration [35]. Pulmonary infections are the major cause of RF and death, and associated immune defect can facilitate respiratory infection and contribute to bronchiectasis development. An early diagnosis of pulmonary complications in AT patients is mandatory to significantly reduce morbidity and mortality [36].

\section{Tetanus and botulism}

The World Health Organization has announced that in the 2007-2017 period the total number of reported cases of tetanus was $12,000-20,000$ cases per year. Tetanus is acquired through the infection of a cut or wound with the spores of the anaerobic bacterium Clostridium tetani, and most cases occur within 14 days after initial infection. Spasms and stiffness are hallmarks of the disease. If not treated in time with tetanus immunoglobulins and hospitalization in an intensive setting, it leads to death due to RF in $100 \%$ of cases. There is an increased risk of tetanus in adult males and adolescents undergoing circumcision due to decreasing immunity and limited opportunities to receive booster doses in many countries $[37,38]$.

Botulism is a serious disease caused by a nerve toxin produced by the anaerobic, spore-producing Clostridium botulinum, which inhibits the release of acetylcholine at the presynaptic level. Three forms of botulism are distinguished according to the site of production of toxins: food, injury, and intestinal botulism (infant and adult). Clinical manifestations include bulbar symptoms, nasal voice, blurred vision, ophthalmoparesis, and autonomic dysfunctions such as dry mouth, constipations, and urinary retention. In Europe, in the 2007-2017 period, 84 to 125 cases per year were reported, with a mortality rate of 3-9\%. Like tetanus, it leads to death due to RF if not treated in time with botulism immunoglobulins and hospitalization in an intensive care unit (ICU). Correct and timely recognition of the infection significantly reduces mortality $[39,40]$.

\section{Neuromuscular disorders}

NMDs are a heterogeneous group of disorders characterized by impairment at the level of motor neurons, peripheral nerve, neuromuscular junction, or skeletal muscle. They include acquired or inherited forms, with very variable age and clinical features at onset, and very different courses and prognoses. If 
muscle weakness involves the diaphragm and accessory respiratory muscles, it leads to RF more or less early in the patient's life, often also facilitated by a severe scoliosis [41]. Table 1 lists the NMDs constantly associated with very early RF. Table 2 reports the NMDs in which RF develops with a slowly progressive course, requiring ventilatory support at a variable age, and with different rates of occurrence [42-44].

Restrictive RF is the leading cause of death in ALS patients [45]; in some cases it may represent its onset. SMA has a significant impact on the respiratory system, depending on the severity of loss of muscle function [5]. SMA type 1 (non-sitters) and type 2 (sitters) patients need more active surveillance and management, whereas a minority of ambulant SMA type 3 patients (walkers) may have decreased cough effectiveness with upper respiratory infections, sleep apnea, or hypoventilation.

Among acquired polyneuropathies, patients with GBS are often at risk of RF. Predictors are rapid course, severe muscle weakness at hospital admission, bulbar or neck weakness, bilateral facial weakness, or dysautonomia [46]. Respiratory involvement is rare in Charcot-Marie-Tooth disease [47].

MG often causes hypercapnic RF as a manifestation of the disease onset, being diagnosed in the ER or in ICU [41, 48]. Congenital myasthenic syndromes may sometimes present life-threatening respiratory episodes especially in the first decade of life [49].

The group of myopathies at risk of respiratory emergencies is more complex, including dozens of partly overlapping phenotypes, caused by mutations of different genes, and acquired inflammatory forms such as PM and DM. Dystrophinopathies (especially DMD) invariably need a ventilatory support therapy from a young age [50]. Other myopathies at risk are some limb-girdle muscular dystrophies (especially sarcoglycanopathies) and myotonic dystrophy type 1 (DM1). The latter is a complex multi-systemic disease, in which cardiomyopathy and disturbances of central breathing regulation coexist, which make ventilatory management difficult [51]. The autosomal dominant facioscapulohumeral muscular dystrophy (FSHD), related to the $4 \mathrm{q}$ region, may develop

Table 1 Neuromuscular disorders with respiratory failure at birth or within the first year of life
Table 2 Neuromuscular disorders with chronic respiratory failure in infant-to-adult life

\section{Rate of occurrence of Diseases}

respiratory failure

Unavoidable

Duchenne muscular dystrophy (DMD)

Amyotrophic lateral sclerosis (ALS)

Some muscular dystrophies (e.g., sarcoglycanopathies)

Some myofibrillar myopathies (e.g., HMERF)

Frequent

Spinal muscular atrophy type 2 (SMA2)

Myotonic dystrophy type 1 (DM1)

Late-onset Pompe disease (LOPD)

Guillain-Barré syndrome (GBS)

Myasthenia gravis (MG)

Facioscapulohumeral muscular dystrophy (FSHD)

Some congenital muscular dystrophies (e.g., Ullrich CMD)

Some limb-girdle muscular dystrophies (LGMD) (e.g., calpainopathy, FKRP)

Some congenital myopathies (e.g., centronuclear myopathy)

Congenital myasthenic syndromes

Occasional Becker muscular dystrophy (BMD)

Some types of Charcot-Marie-Tooth disease (e.g., CMT type 1B and 4)

Inflammatory myopathies

Spinal muscular atrophy type 3 (SMA3)

Some congenital myopathies

Some mitochondrial diseases

Rare

Oculopharyngeal muscular dystrophy
(OPMD)
CMT
Chronic inflammatory demyelinating
polyneuropathy (CIDP)

ARDS generally in early-onset cases [52]. Among metabolic myopathies, Pompe disease caused by mutations of the acid alpha glucosidase enzyme gene is still at risk of $\mathrm{RF}$, despite the availability of enzyme replacement therapy for over 10 years. About a third of cases with infantileonset (IOPD) in the first year of life require ventilatory support, as well as a minority of cases with adult form [53]. Some adults start with dyspnea and hypercapnic RF and can be diagnosed after acute ventilatory failure. However, all patients should be carefully monitored for respiratory function. Acute or subacute inflammatory myopathies, especially the autoimmune necrotizing myopathies with positive anti-SRP antibodies, can rapidly evolve into respiratory emergencies.

When physicians working in the ER meet a patient with hypercapnic RF, they must always try to gather detailed information on the exact type of neuromuscular disease already diagnosed, since prognosis and treatment may greatly differ. Furthermore, some patients with NMDs may present with 
acute or subacute RF even before significant limb muscle weakness (Table 3 ).

\section{Clinical management and treatment}

\section{Acute respiratory failure in slowly progressive neurological diseases}

\section{Movement disorders}

Although advice on the management of ARF in PD is difficult, due to varying and conflicting results of previous studies, a contraindication to noninvasive ventilation (NIV) may exist in the acute setting, and positive pressure ventilation via endotracheal intubation (ETI) may constitute the only choice for treating patients who require ventilatory support. Moreover, abnormally reduced vocal cord movement amplitude, laryngeal tremor, and oropharyngeal dysfunction can produce $\mathrm{UAO}$, which in turn can be associated with difficult intubation and require bronchoscopy assistance during the procedure [54].

At ER admission, patients with myoclonus may necessitate invasive mechanical ventilation (IMV) via ETI, in the event of ARDS [55].

In patients with Huntington's disease, death usually results from respiratory complications, in particular aspiration pneumonia which accounts for approximately 55\% of deaths, followed by "suffocation" and pulmonary embolism [56]. As these patients commonly suffer from severe dysphagia, ETI and IMV are suggested at the onset of ARF requiring ventilator support, to protect the airways from the risk of inhalation.

\section{Neuromuscular disorders}

Development of respiratory infections may be a lifethreatening event in NMDs patients, favored by mucous encumbrance and further weakening of respiratory muscles, which lead to ARF $[13,57]$. Additionally, several myopathies are associated with cardiac dysfunction such as dilated cardiomyopathy [58], which may contribute to the development of ARF, leading to cardiogenic pulmonary edema (Table 4). Finally, pneumothorax, fat embolism, and abuse of sedative

Table 3 Adult neuromuscular disorders which may present with respiratory failure at onset drugs are rare but serious, life-threatening complications in these patients.

The identification of subjects at high risk of RF and timely provision of inspiratory (i.e., NIV) and expiratory aids (i.e., manual and mechanical cough assistance) are critical for preventing severe complications [15, 59-61]. It follows that a proactive clinical approach should be taken to recognize pulmonary problems prior to the onset of respiratory compromise (Table 5). In these patients, the best and easiest parameter used to monitor respiratory muscle strength is FVC. Patients who have an $\mathrm{FVC}<50 \%$ of predicted value should be trained in protocols that allow successful home treatment managed by well-trained family members or healthcare professionals during respiratory exacerbations [50,62].

In the case of ARF, the patients should receive 24-h NIV and pulse oximetry monitoring. When oxygen saturation on room air falls below 95\%, secretion removal should be aggressively induced using manual and mechanical cough assistance until oxygen saturation returns to the $95 \%$ range. Oxygen should not be used to correct hypoxemia, as it can worsen hypercapnia and does not allow the recognition of severe hypercapnia with the pulse oximetry. A dramatic reduction in the need for hospitalization and a prolongation of life expectancy have been reported in well-trained patients [13, 15]. Moreover, services providing active treatment by healthcare professionals at a patient's home are an effective alternative to hospital admission [62]. Additionally, in the case of suspected respiratory infections, early use of antibiotics is mandatory, in particular if pulse oximetry is below $95 \%$ in room air (Table 6).

If home respiratory management fails, patients must be hospitalized, NIV remaining the first-line ventilator strategy. Moreover, if bronchial encumbrance is present, cough assistance must be applied aggressively. Patient selection is very important to the success of this noninvasive strategy. Severe bulbar dysfunction increases patient risk for aspiration, hampers the elimination of airway secretions, and increases resistance to airflow impeding successful use of NIV [59, 63]. Moreover, the use of noninvasive strategies should never delay ETI for patients where this approach has failed [42].

To receive close monitoring and aggressive noninvasive respiratory assistance, patients should be placed in a unit where nurses are adequately trained and a physician is physically present onsite 24 hours a day. Monitoring must be tailored and personalized according to the clinical severity of each case, but it must include $\mathrm{PaCO}_{2}$ measurements if supplemental oxygen is used to correct hypoxemia (i.e., capillary $\mathrm{CO}_{2}$ in less severe diseases and indwelling arterial line in most severe cases) [42, 64].

If NIV fails or is contraindicated (Table 7), patients with progressive NMDs should be intubated as a short-term measure. In this case, appropriate assessment for a difficult intubation due to reduced mouth opening, macroglossia, or to limited mobility of the cervical spine is very important. If any conditions predicting difficult airway management are 
Table 4 Neuromuscular disorders associated to cardiomyopathy

\begin{tabular}{ll}
\hline Neuromuscular disorder & Cardiac disorder \\
\hline DMD, BMD & $\begin{array}{c}\text { Dilated cardiomyopathy (more frequent), } \\
\text { conduction disorders, arrhythmias } \\
\text { Conduction disorders and arrhythmias } \\
\text { (more frequent), dilated cardiomyopathy }\end{array}$ \\
$\begin{array}{l}\text { Myotonic dystrophy } \\
\text { Emery-Dreifuss muscular dystrophy } \\
\text { Myofibrillar myopathies } \\
\text { Mitochondrial myopathies }\end{array}$ & $\begin{array}{c}\text { Conduction disorders and arrhythmias } \\
\text { (more frequent), hypertrophic cardiomyopathy, } \\
\text { Pompe disease }\end{array}$ \\
nipid storage myopathies & $\begin{array}{l}\text { Hypertrophic cardiomyopathy (in IOPD) } \\
\text { Dilated cardiomyopathy, hypertrophic cardiomyopathy }\end{array}$ \\
\hline
\end{tabular}

present, intubation should be performed considering applicable guidelines and avoiding emergent intubation [65].

After recovery from the acute illness, these patients should be promptly extubated. Unfortunately, because of respiratory muscles weakness and inability to handle bronchial secretions, a substantial proportion of patients fail to pass spontaneous breathing trials [66]. Preventive application of NIV combined with assisted coughing after extubation provides a clinically important advantage by averting the need for reintubation and shortening the ICU stay. Indications for a tracheotomy can be evaluated, but it should not be considered in the acute phase, rather only in the case of multiple failures of weaning protocol $[67,68]$.

\section{De novo acute respiratory failure}

\section{Stroke}

Following stroke, hypocapnia is associated with poor outcome [69]. Current guidelines produced by European Stroke

Table 5 Causes of ARF in patients with chronic neuromuscular disorders

\begin{tabular}{|c|c|}
\hline Rate of occurrence & Pulmonary problems leading to ARF \\
\hline Common & $\begin{array}{l}\text { Upper respiratory tract infections } \\
\text { (influenza, parainfluenza, bacterial infections) }\end{array}$ \\
\hline Less common & $\begin{array}{l}\text { Community-acquired pneumonia } \\
\text { Ventilator-associated pneumonia } \\
\text { Aspiration pneumonia } \\
\text { Atelectasis }\end{array}$ \\
\hline Uncommon & $\begin{array}{l}\text { Cardiogenic pulmonary edema } \\
\text { Pneumothorax } \\
\text { Lung adipose embolism } \\
\quad \text { (in case of bone fractures) } \\
\text { Drug abuse or overdose } \\
\quad \text { (e.g., benzodiazepines, opiates, } \\
\text { alcohol, anesthetics) } \\
\text { Pulmonary embolism } \\
\text { Tracheo-arterial fistula } \\
\text { Gastric or colonic bloating }\end{array}$ \\
\hline
\end{tabular}

Organization, American Stroke Association, and National Institute for Health and Care Excellence support oxygen supplementation if $\mathrm{SpO}_{2}$ falls below 94\%. Although, to date, no trial has tested its utility in severe stroke, IMV via ETI is indicated in conditions such as decreased consciousness level (Glasgow Coma Scale, GCS, $\leq 8$ ), evidence of brainstem dysfunction, or any other cause of a threatened airway, to prevent aspiration pneumonia, in the event of ARF due to pulmonary edema (neurogenic or cardiogenic), generalized seizures or status epilepticus, and apneic episodes [19]. Due to the risk of rapid variation of the patient's clinical status, continuous monitoring of systemic oxygenation through pulse oximetry is essential. Mechanically ventilated patients should undergo regular arterial blood gas monitoring. The mortality rate of patients with stroke undergoing ETI has been variously reported to be between 40 and $80 \%$ regardless of the causes of intubation, with only about $50 \%$ surviving 30 days and $30 \%$ surviving 1 year [70]. Predictors of death include low GCS at intubation and absent pupillary light reflexes. 15-35\% of stroke patients admitted at the ICU require tracheostomy for difficult weaning. Patients who survive may achieve good functional outcome, with more than two-thirds regaining normal activities of daily living [71].

\section{Convulsive status epilepticus}

ETI and IMV allow to maintain the normocapnia and normoxia, to prevent pulmonary aspiration, and also to use intravenous anesthetics to treat epilepsy. Delay in intubation is associated with increased mortality. Therefore, ETI can be avoided only if recovery of consciousness is rapid [72].

\section{Traumatic brain injury}

In severe TBI (GCS < 9), reduced morbidity and mortality are obtained avoiding secondary brain damage due to low blood pressure, intracranial hypertension, hypoxemia, and hypercapnia. For these reasons, the patient must be intubated, and IMV must be set to maintain 
Table 6 Recommendations for home management of an infectious acute respiratory disease

- During the infectious exacerbation, the value of $\mathrm{SaO}_{2}$ should be continuously monitored using the pulse oximeter with the aim of maintaining an $\mathrm{SaO}_{2}$ ideally $>95 \%$ or at least $>92 \%$ in ambient air

- It may be necessary to use the ventilator 24 hours a day to avoid hypoventilation and/or $\mathrm{SaO}_{2}<95 \%$

- To avoid the development of pressure sores in the support points of the mask, the use of two different masks should be alternated, and hydrocolloid patches should be used to protect the support points

- To reduce dyspnea and enhance the value of $\mathrm{SaO}_{2}$, the caregiver can increase the respiratory rate by $2-4$ points, the positive end-expiratory pressure (PEEP) by 1-2 points, and, in the case of pressometric ventilation, the inspiratory pressure by $1-2$ points. To avoid gastric distension, maximum pressure in the airways should not rise above $25 \mathrm{~cm} \mathrm{H}_{2} \mathrm{O}$

- When the value of $\mathrm{SaO}_{2}$ falls below $95 \%$, especially when the presence of bronchial secretions is suspected from chest auscultation or due to a sudden change in the parameters of the ventilator (e.g., in the case of reduction of tidal volume if in pressometric ventilation or increase in peak pressure if in volumetric ventilation), manual and/or mechanical cough assistance techniques must be used. In preschool children and in patients with severe dysphagia, it is useful, immediately after using the cough machine, to perform secretion aspiration in the oropharynx with the aid of a mechanical aspirator

- To avoid severe desaturation, $\mathrm{O}_{2}$ can be used but only for short periods (e.g., a few minutes before performing cough assistance maneuvers and/or immediately after). For this purpose, the oxygen source must be connected to the ventilator. However, $\mathrm{O}_{2}$ must never be used without associating it with NIV

- Each febrile episode $>38.5^{\circ} \mathrm{C}$ must be treated with paracetamol and a valid hydration protocol

- An antibiotic should be used early, especially if $\mathrm{SaO}_{2}<95 \%$. It is important that the antibiotic coverage includes atypical bacteria (macrolide or fluoroquinolone). In case of possible inhalation (e.g., in patients with severe dysphagia), a second antibiotic should be associated covering anaerobic bacteria (e.g., amoxicillin associated with clavulanic acid)

- In the case of a respiratory tract infection managed at home, a specialist or a general practitioner should visit the patient ideally once a day or at least every $2-3$ days. This care is mainly aimed at prescribing antibiotic therapy and excluding the presence of hospital admission criteria. It is desirable that the general practitioner maintains telephone contact with a specialist who is competent in home ventilation in order to share the decision-making process

- Hospital admission is recommended if one or more of the following are present:

- Desaturation $<92 \%$ in ambient air

- Need to use $\mathrm{O}_{2}$ to maintain $\mathrm{SaO}_{2}>92 \%$

- Persistence of dyspnea despite the use of a ventilator

- Severe dehydration

- High fever unresponsive to antipyretics and antibiotics

- No response after 1 week of application of the protocol

- Suspected pneumothorax

- Suspected cardiogenic pulmonary edema

- Suspected pulmonary embolism
Table 7 Contraindications to NIV

Uncooperative patient

Reduced level of consciousness

Delirium with restlessness or agitation

Severe dysphagia

Excessive secretions not managed by mechanical cough assistance

Severe hypoxemia $\left(\mathrm{PaO}_{2}<60 \mathrm{mmHg}\right.$ with $\left.\mathrm{FiO}_{2}>0.6\right)$

Undrained pneumothorax

Coexistence of two other organ failures

normal capnia and oxygenation, to allow the patient to be sedated, reducing intracranial pressure and preventing pulmonary aspiration [73]. Moreover, patients with TBI frequently suffer from lung complications and ARDS, which can be multi-etiological (i.e., aspiration pneumonia, pulmonary contusion related to chest trauma, neurogenic pulmonary edema, transfusion-related acute lung injury). These complications represent a further indication for IMV. Unfortunately, ventilator strategies can have effect on cerebral perfusion and represent a potential burden for iatrogenic secondary brain damage [74]. In particular, when a concomitance of TBI and ARDS occurs, the ventilatory management can be very challenging as ventilatory targets are often in conflict among each other. Ventilator strategies commonly used in patients with ARDS induce a relevant increase in intrathoracic pressures, which may reduce cerebral venous return to the right atrium. This phenomenon may cause a significant increase in intracranial pressure and a harmful decrease in cerebral perfusion. In order to avoid iatrogenic secondary brain damage due to these mechanical ventilation consequences on cerebral dynamics, intracranial pressure monitoring is indicated [75].

\section{Spinal cord injury}

ETI and IMV are always required in patients with complete lesion above $\mathrm{C} 5$, while intubation can be avoided in patients with incomplete injury and lesion below $\mathrm{C} 5$. In these patients, to assess the need for invasive or noninvasive ventilatory assistance, it is essential to monitor not only pulse-oximetry but also $\mathrm{CO}_{2}$, vital capacity and maximum inspiratory pressure (MIP). A reduction in vital capacity to below $15 \mathrm{~mL} / \mathrm{kg}$, a maximum inspiratory pressure below $-20 \mathrm{~cm} \mathrm{H}_{2} \mathrm{O}$, and an increase in $\mathrm{pCO}_{2}$ are markers for the need for mechanical ventilation [76]. In the first year after cervical injury, respiratory function may improve spontaneously, often allowing weaning from mechanical ventilation. However, after the first year, improvements in respiratory function are usually minimal or absent. 


\section{Diaphragm paralysis}

Phrenic neuropathies are a significant cause of respiratory dysfunction. Phrenic neuropathy has been associated with a variety of causes (e.g., brachial plexopathy, infections, amiodarone, chemotherapy agents, thymectomy, cardiac surgery, thoracotomy, internal jugular catheter insertion, interscalene block). However, in many patients, the cause of phrenic nerve damage remains unclear (idiopathic phrenic neuropathy) [77].

Patients with unilateral diaphragm paralysis are often asymptomatic but may develop dyspnea on exertion or when they are supine, particularly if there is abdominal distension (e.g., obesity or pregnancy), or in the case of coexisting heart or lung disease. In the asymptomatic patients, unilateral diaphragm paralysis may be discovered as an incidental radiographic finding of an elevated hemidiaphragm [78]. Patients with bilateral diaphragmatic paralysis develop severe orthopnea with a supine drop in forced vital capacity of more than $30 \%$ and progressive nocturnal hypoventilation, which may culminate in acute presentation with hypercapnic RF [79].

\section{Neuromuscular disorders}

Myasthenic crisis is observed in approximately $20 \%$ of MG patients and may result in ARF caused by the combination of upper airway obstruction and acute hypoventilation due to incapacitating weakness of both bulbar and inspiratory muscles [80]. The evidence for use of invasive ventilation via ETI is strong and has been recommended in most of the series published so far; a mortality rate in patients receiving invasive ventilation has been reported between 4 and 6\%. Extubation may fail in up to one quarter of patients, and presence of atelectasis has been reported to be strongly associated with extubation failure [81]. Although NIV may be inappropriate in patients with ARF unless upper airway function is well preserved, this option seems desirable in patients with myasthenic crisis because of the increased risk of prolonged IMV complicated with ventilator-associated pneumonia and other systemic complications $[82,83]$. Administering NIV with a relatively low inspiratory-pressure range of $10-16 \mathrm{~cm} \mathrm{H}_{2} \mathrm{O}$ can be effective in preventing the need for ETI in these patients. Severe hypercapnia $\left(\mathrm{PaCO}_{2}>50 \mathrm{mmHg}\right)$ and high serum bicarbonate concentration at admission have been considered predictors of NIV failure [1,84].

In order to early identify GBS patients at risk for ARF requiring ventilatory support, the "20/30/40 rule" has been proposed: intubation is indicated if the $\mathrm{FVC}<$ $20 \mathrm{~mL} / \mathrm{kg}$, the MIP $<30 \mathrm{~cm} \mathrm{H}_{2} \mathrm{O}$, and the maximal expiratory pressure (MEP) $<40 \mathrm{~cm} \mathrm{H}_{2} \mathrm{O}$ [9]. The application of NIV in GBS patients is not a safe option for several reasons: (a) patients usually remain extremely weak and require full ventilator assistance for many days, and (b) the manifestations of dysautonomia get worse as RF becomes more severe. Between 25 and $50 \%$ of patients require ETI and IMV [85]. Moreover, emergency intubation should be avoided because it can induce life-threatening complications from dysautonomia, including labile blood pressure, cardiac arrhythmias, and fatal hyperkalemia with the use of succinylcholine. The mortality rate of severe GBS causing neuromuscular ARF may still reach 5-10\%; in addition, $20 \%$ of survivors may suffer from long-term disability [86].

\section{Conclusions}

The management of ARF in patients with neurological diseases is a strong challenge and frequently occurs in the ICU setting, a neurological ward, or even at home. Treatment must be tailored on a personalized level by an expert neurointensivist, considering all the past medical history as well as concomitant medical events. Moreover, in the recent years, intensive care medicine has progressed considerably, and new technologies continuously improve ventilatory treatment and survival [87]. In the case of risk of acute-on-chronic $\mathrm{RF}$, appropriate education of caregivers and periodic followup are necessary to optimize domiciliary assistance and to remove barriers to its application $[88,89]$.

Although standards of care have been identified for many acute and chronic NMDs requiring appropriate management of ARF and many guidelines have been elaborated, there are no randomized trials assessing the practice for the use of noninvasive versus invasive mechanical ventilation [90]. There is much work yet to be done in designing and conducting clinical trials to provide evidence-based data to anticipate variations in treatment responses according to disease, onset type (acute onset versus acute exacerbations on chronic NMDs), and presence or absence of bulbar dysfunction.

Finally, increasing recognition of e-health technologies as potential tools in enhancing healthcare quality has recently led to the proposal of innovative technologies and tele-monitoring assistance in the respiratory care of NMDs patients [91, 92]. Although these are pilot applications, encouraging results have been provided, and further studies involving larger cohorts and multidisciplinary teams are needed with the final aim to prevent acute respiratory events.

Funding information No specific grant was received from any funding agency in the public, commercial, or not-for-profit sectors.

\section{Compliance with ethical standards}

Conflict of interest The authors declare that they have no conflict of interest. 


\section{References}

1. Rabinstein AA, Wijdicks EF (2003) Warning signs of imminent respiratory failure in neurological patients. Semin Neurol 23:97104

2. Boentert M, Wenninger S, Sansone VA (2017) Respiratory involvement in neuromuscular disorders. Curr Opin Neurol 30:529-537

3. Mann JR, Royer JA, Mcdermott S, Hardin JW, Ozturk O, Street N (2015) Hospitalizations and emergency room visits for adolescents and young adults with muscular dystrophy living in South Carolina. Muscle Nerve 52:714-721

4. Kao WT, Tseng YH, Jong YJ, Chen TH (2019) Emergency room visits and admission rates of children with neuromuscular disorders: a 10-year experience in a medical center in Taiwan. Pediatr Neonatol 60:405-410

5. Finkel RS, Mercuri E, Meyer OH, Simonds AK, Schroth MK, Graham RJ, Kirschner J, Iannaccone ST, Crawford TO, Woods S, Muntoni F, Wirth B, Montes J, Main M, Mazzone ES, Vitale M, Snyder B, Quijano-Roy S, Bertini E, Davis RH, Qian Y, Sejersen T, SMA Care group (2018) Diagnosis and management of spinal muscular atrophy: part 2: pulmonary and acute care; medications, supplements and immunizations; other organ systems; and ethics. Neuromuscul Disord 28:197-207

6. Messina S, Vita GL (2018) Clinical management of Duchenne muscular dystrophy: the state of the art. Neurol Sci 39:1837-1845

7. Rahbek J, Werge B, Madsen A, Marquardt J, Steffensen BF, Jeppesen J (2005) Adult life with Duchenne muscular dystrophy: observations among an emerging and unforeseen patient population. Pediatr Rehabil 8:17-28

8. Abbott D, Carpenter J, Bushby K (2012) Transition to adulthood for young men with Duchenne muscular dystrophy: research from the UK. Neuromuscul Disord 22:445-446

9. Mehta S (2006) Neuromuscular disease causing acute respiratory failure. Respir Care 51:1016-1021

10. Mador MJ (1991) Respiratory muscle fatigue and breathing pattern. Chest 100:1430-1435

11. Laghi F, Tobin MJ (2003) Disorders of the respiratory muscles. Am J Respir Crit Care Med 168:10-48

12. Buyse B, Demedts M, Meekers J, Vandegaer L, Rochette F, Kerkhofs L (1997) Respiratory dysfunction in multiple sclerosis: a prospective analysis of 60 patients. Eur Respir J 10:139-145

13. Tzeng AC, Bach JR (2000) Prevention of pulmonary morbidity for patients with neuromuscular disease. Chest 118:1390-1396

14. Ambrosino N, Confalonieri M, Crescimanno G, Vianello A, Vitacca M (2013) The role of respiratory management of Pompe disease. Respir Med 107:1124-1132

15. Bach JR, Ishikawa Y, Kim H (1997) Prevention of pulmonary morbidity for patients with Duchenne muscular dystrophy. Chest 112: 1024-1028

16. Mazzeo AT, La Monaca E, Di Leo R, Vita G, Santamaria LB (2011) Heart rate variability: a diagnostic and prognostic tool in anesthesia and intensive care. Acta Anaesthesiol Scand 55:797-811

17. Pollock RD, Rafferty GF, Moxham J, Kalra L (2013) Respiratory muscle strength and training in stroke and neurology: a systematic review. Int J Stroke 8:124-130

18. Lima IN, Fregonezi GA, Melo R, Cabral EE, Aliverti A, Campos TF, Ferreira GM (2014) Acute effects of volume-oriented incentive spirometry on chest wall volumes in patients after a stroke. Respir Care 59:1101-1107

19. Kirkman MA, Citerio G, Smith M (2014) The intensive care management of acute ischemic stroke: an overview. Intensive Care Med 40:640-653

20. Menezes KK, Nascimento LR, Avelino PR, Alvarenga MTM, Teixeira-Salmela LF (2018) Efficacy of interventions to improve respiratory function after stroke. Respir Care 63:920-933
21. Chapman C, Morgan P, Cadilhac DA, Purvis T, Andrew NE (2018) Risk factors for the development of chest infections in acute stroke: a systematic review. Top Stroke Rehabil 25:445-458

22. Sutter R, Dittrich T, Semmlack S, Rüegg S, Marsch S, Kaplan PW (2018) Acute systemic complications of convulsive status epilepticus-A systematic review. Crit Care Med 46:138-145

23. Davison DL, Terek M, Chawla LS (2012) Neurogenic pulmonary edema. Crit Care 16:212

24. van Wessem KJP, Leenen LPH (2018) Incidence of acute respiratory distress syndrome and associated mortality in a polytrauma population. Trauma Surg Acute Care Open 3:e000232

25. Krishnamoorthy V, Hough CL, Vavilala MS, Komisarow J, Chaikittisilpa N, Lele AV, Raghunathan K, Creutzfeldt CJ (2019) Tracheostomy after severe acute brain injury: trends and variability in the USA. Neurocrit Care 30:546-554

26. Zakrasek EC, Nielson JL, Kosarchuk JJ, Crew JD, Ferguson AR, McKenna SL (2017) Pulmonary outcomes following specialized respiratory management for acute cervical spinal cord injury: a retrospective analysis. Spinal Cord 55:559-565

27. Berlly M, Shem K (2007) Respiratory management during the first five days after spinal cord injury. J Spinal Cord Med 30:309-318

28. Jackson AB, Groomers TE (1994) Incidence of respiratory complications following SCI. Arch Phys Med Rehabil 75:270-275

29. Tzelepis GE, McCool FD (2015) Respiratory dysfunction in multiple sclerosis. Respir Med 109:671-679

30. Britton PN, Eastwood K, Paterson B, Durrheim DN, Dale RC, Cheng AC, Kenedi C, Brew BJ, Burrow J, Nagree Y, Leman P, Smith DW, Read K, Booy R, Jones CA, Australasian Society of Infectious Diseases (ASID); Australasian College of Emergency Medicine (ACEM); Australian and New Zealand Association of Neurologists (ANZAN); Public Health Association of Australia (PHAA) (2015) Consensus guidelines for the investigation and management of encephalitis in adults and children in Australia and New Zealand. Intern Med J 45:563-576

31. Torsney KM, Forsyth D (2017) Respiratory dysfunction in Parkinson's disease. J R Coll Physicians Edinb 47:35-39

32. Baille G, De Jesus AM, Perez T, Devos D, Dujardin K, Charley CM, Defebvre L, Moreau C (2016) Ventilatory dysfunction in Parkinson's disease. J Parkinsons Dis 6:463-471

33. Simons JA (2017) Swallowing dysfunctions in Parkinson's disease. Int Rev Neurobiol 134:1207-1238

34. Sriranjini SJ, Pal PK, Krishna N, Sathyaprabha TN (2010) Subclinical pulmonary dysfunction in spinocerebellar ataxias 1,2 and 3. Acta Neurol Scand 122:323-328

35. McGrath-Morrow SA, Gower WA, Rothblum-Oviatt C, Brody AS, Langston C, Fan LL, Lefton-Greif MA, Crawford TO, Troche M, Sandlund JT, Auwaerter PG, Easley B, Loughlin GM, Carroll JL, Lederman HM (2010) Evaluation and management of pulmonary disease in ataxia-telangiectasia. Pediatr Pulmonol 45:847-859

36. Bhatt JM, Bush A, van Gerven M, Nissenkorn A, Renke M, Yarlett L, Taylor M, Tonia T, Warris A, Zielen S, Zinna S, Merkus PJ, European Respiratory Society (2015) ERS statement on the multidisciplinary respiratory management of ataxia telangiectasia. Eur Respir Rev 24:565-581

37. Zibners L (2017) Diphtheria, pertussis, and tetanus: evidence-based management of pediatric patients in the emergency department. Pediatr Emerg Med Pract 14:1-24

38. Pottie K, Mayhew AD, Morton RL, Greenaway C, Akl EA, Rahman P, Zenner D, Pareek M, Tugwell P, Welch V, Meerpohl J, Alonso-Coello P, Hui C, Biggs BA, Requena-Méndez A, Agbata E, Noori T, Schünemann HJ (2017) Prevention and assessment of infectious diseases among children and adult migrants arriving to the European Union/European Economic Association: a protocol for a suite of systematic reviews for public health and health systems. BMJ Open 7:e014608 
39. Witoonpanich R, Vichayanrat E, Tantisiriwit K, Wongtanate M, Sucharitchan N, Oranrigsupak P, Chuesuwan A, Nakarawat W, Tima A, Suwatcharangkoon S, Ingsathit A, Rattanasiri S, Wananukul W (2010) Survival analysis for respiratory failure in patients with food-borne botulism. Clin Toxicol (Phila) 48:177-183

40. Chatham-Stephens K, Fleck-Derderian S, Johnson SD, Sobel J, Rao AK, Meaney-Delman D (2017) Clinical features of foodborne and wound botulism: a systematic review of the literature, 19322015. Clin Infect Dis 66(Suppl 1):S11-S16

41. Howard RS (2016) Respiratory failure because of neuromuscular disease. Curr Opin Neurol 29:592-601

42. Racca F, Del Sorbo L, Mongini T, Vianello A, Ranieri VM (2010) Respiratory management of acute respiratory failure in neuromuscular diseases. Minerva Anestesiol 76:51-62

43. Sansone VA, Racca F, Ottonello G, Vianello A, Berardinelli A, Crescimanno G, Casiraghi JL, Italian SMA Family Association (2015) 1st Italian SMA Family Association Consensus Meeting: management and recommendations for respiratory involvement in spinal muscular atrophy (SMA) types I-III, Rome, Italy, 30-31 January 2015. Neuromuscul Disord 25:979-989

44. Buu MC (2017) Respiratory complications, management and treatments for neuromuscular disease in children. Curr Opin Pediatr 29: 326-333

45. de Carvalho M, Swash M, Pinto S (2019) Diaphragmatic neurophysiology and respiratory markers in ALS. Front Neurol 10:143

46. Green C, Baker T, Subramaniam A (2018) Predictors of respiratory failure in patients with Guillain-Barré syndrome: a systematic review and meta-analysis. Med J Aust 208:181-188

47. Pareyson D, Marchesi C (2009) Diagnosis, natural history, and management of Charcot-Marie-Tooth disease. Lancet Neurol 8: 654-667

48. Evoli A, Antonini G, Antozzi C, DiMuzio A, Habetswallner F, Iani C, Inghilleri M, Liguori R, Mantegazza R, Massa R, Pegoraro E, Ricciardi R, Rodolico C (2019) Italian recommendations for the diagnosis and treatment of myasthenia gravis. Neurol Sci 40: $1111-1124$

49. Maggi L, Bernasconi P, D’Amico A, Brugnoni R, Fiorillo C, Garibaldi M, Astrea G, Bruno C, Santorelli FM, Liguori R, Antonini G, Evoli A, Bertini E, Rodolico C, Mantegazza R (2019) Italian recommendations for diagnosis and management of congenital myasthenic syndromes. Neurol Sci 40:457-468

50. Birnkrant DJ, Bushby K, Bann CM, Apkon SD, Blackwell A, Colvin MK, Cripe L, Herron AR, Kennedy A, Kinnett K, Naprawa J, Noritz G, Poysky J, Street N, Trout CJ, Weber DR, Ward LM, DMD Care Considerations Working Group (2018) Diagnosis and management of Duchenne muscular dystrophy, part 3: primary care, emergency management, psychosocial care, and transitions of care across the lifespan. Lancet Neurol 17:445-455

51. Hawkins AM, Hawkins CL, Abdul Razak K, Khoo TK, Tran K, Jackson RV (2019) Respiratory dysfunction in myotonic dystrophy type 1: a systematic review. Neuromuscul Disord 29:198-212

52. Moreira S, Wood L, Smith D, Marini-Bettolo C, Guglieri M, McMacken G, Bailey G, Mayhew A, Muni-Lofra R, Eglon G, Williams M, Straub V, Lochmüller H, Evangelista T (2017) Respiratory involvement in ambulant and non-ambulant patients with facioscapulohumeral muscular dystrophy. J Neurol 264: 1271-1280

53. Boentert M, Prigent H, Vardi K, Jones HN, Mellies U, Simonds AK, Wenninger S, Barrot Cortés E, Confalonieri M (2016) Practical recommendations for diagnosis and management of respiratory muscle weakness in late-onset Pompe disease. Int J Mol Sci 17(10) pii:E1735

54. Brown LK (1994) Respiratory dysfunction in Parkinson's disease. Clin Chest Med 15:715-727

55. Degeneffe A, Dagonnier M, D'hondt A, Elosegi JA (2018) A case report of rigidity and recurrent lower limb myoclonus: progressive encephalomyelitis rigidity and myoclonus syndrome, a chameleon. BMC Neurology 18:173

56. Heemskerk A, Roos RA (2012) Aspiration pneumonia and death in Huntington's disease. PloS Curr 4:RRN1293

57. Poponick JM, Jacobs I, Supinski G, DiMarco AF (1997) Effect of upper respiratory tract infection in patients with neuromuscular disease. Am J Respir Crit Care Med 156:659-664

58. Goodwin FC, Muntoni F (2005) Cardiac involvement in muscular dystrophies: molecular mechanisms. Muscle Nerve 32:577-588

59. Vianello A, Corrado A, Arcaro G, Gallan F, Ori C, Minuzzo M, Bevilacqua M (2005) Mechanical insufflation-exsufflation improves outcomes for neuromuscular disease patients with respiratory tract infections. Am J Phys Med Rehabil 84:83-88

60. Gregoretti C, Pisani L, Cortegiani A, Ranieri VM (2015) Noninvasive ventilation in critically ill patients. Crit Care Clin 31:435-457

61. Chatwin M, Toussaint M, Gonçalves MR, Sheers N, Mellies U, Gonzales-Bermejo J, Sancho J, Fauroux B, Andersen T, Hov B, Nygren-Bonnier M, Lacombe M, Pernet K, Kampelmacher M, Devaux C, Kinnett K, Sheehan D, Rao F, Villanova M, Berlowitz D, Morrow BM (2018) Airway clearance techniques in neuromuscular disorders: a state of the art review. Respir Med 136:98-110

62. Vianello A, Savoia F, Pipitone E, Nordio B, Gallina G, Paladini L, Concas A, Arcaro G, Gallan F, Pegoraro E (2013) "Hospital at home" for neuromuscular disease patients with respiratory tract infection: a pilot study. Respir Care 58:2061-2068

63. Servera E, Sancho J, Zafra MJ, Català A, Vergara P, Marın J (2005) Alternatives to endotracheal intubation for patients with neuromuscular diseases. Am J Phys Med Rehabil 84:851-857

64. Kneyber MCJ, de Luca D, Calderini E, Jarreau PH, Javouhey E, Lopez-Herce J, Hammer J, Macrae D, Markhorst DG, Medina A, Pons-Odena M, Racca F, Wolf G, Biban P, Brierley J, Rimensberger PC, section Respiratory Failure of the European Society for Paediatric and Neonatal Intensive Care (2017) Recommendations for mechanical ventilation of critically ill children from the Paediatric Mechanical Ventilation Consensus Conference (PEMVECC). Intensive Care Med 43:1764-1780

65. Racca F, Mongini T, Wolfler A, Vianello A, Cutrera R, Del Sorbo L, Capello EC, Gregoretti C, Massa R, De Luca D, Conti G, Tegazzin V, Toscano A, Ranieri VM (2013) Recommendations for anesthesia and perioperative management of patients with neuromuscular disorders. Minerva Anestesiol 79:419-433

66. Hill NS (2006) Neuromuscular disease in respiratory and critical care medicine. Respir Care 51:1065-1071

67. Bach JR, Gonçalves MR, Hamdani I, Winck JC (2010) Extubation of patients with neuromuscular weakness: a new management paradigm. Chest 137:1033-1039

68. Vianello A, Arcaro G, Braccioni F, Gallan F, Marchi MR, Chizio S, Zampieri D, Pegoraro E, Salvador V (2011) Prevention of extubation failure in high-risk patients with neuromuscular disease. J Crit Care 26:517-524

69. Rout MW, Lane DJ, Wollner L (1971) Prognosis in acute cerebrovascular accidents in relation to respiratory pattern and blood gas tensions. Br Med J 3:7-9

70. Milhaud D, Popp J, Thouvenot E, Heroum C, Bonafé A (2004) Mechanical ventilation in ischemic stroke. J Stroke Cerebrovasc Dis 4:183-188

71. Bosel J (2014) Tracheostomy in stroke patients. Curr Treat Options Neurol 16:274

72. Vohra TT, Miller JB, Nicholas KS, Varelas PN, Harsh DM, Durkalski V, Silbergleit R, Wang HE, Neurological Emergencies Treatment Trials (NETT) Investigators (2015) Endotracheal intubation in patients treated for prehospital status epilepticus. Neurocrit Care 23:33-43 
73. Seder DB, Riker RR, Jagoda A, Smith WS, Weingart SD (2012) Emergency neurological life support: airway, ventilation, and sedation. Neurocrit Care 17(Suppl 1):S4-20

74. Nyquist P, Stevens RD, Mirski MA (2008) Neurologic injury and mechanical ventilation. Neurocrit Care 9:400-408

75. Della Torre V, Badenes R, Corradi F, Racca F, Lavinio A, Matta B, Bilotta F, Robba C (2017) Acute respiratory distress syndrome in traumatic brain injury: how do we manage it? J Thorac Dis 9:53685381

76. Como JJ, Sutton ER, McCunn M, Dutton RP, Johnson SB, Aarabi B, Scalea TM (2005) Characterizing the need for mechanical ventilation following cervical spinal cord injury with neurologic deficit. J Trauma 59:912-916

77. Podnar S (2015) Idiopathic phrenic neuropathies: a case series and review of the literature. Muscle Nerve 52:986-992

78. Baltzan MA, Scott AS, Wolkove N (2012) Unilateral hemidiaphragm weakness is associated with positional hypoxemia in REM sleep. J Clin Sleep Med 8:51-58

79. Armstrong JD (2012) Dysfunction of the diaphragm. N Engl J Med 366:2036-2037

80. Lacomis D (2005) Myasthenic crisis. Neurocrit Care 3:189-194

81. Thomas CE, Mayer SA, Gungor Y, Swarup R, Webster EA, Chang I, Brannagan TH, Fink ME, Rowland LP (1997) Myasthenia crisis: clinical features, mortality, complications and risk factors for prolonged intubation. Neurology 48:1253-1260

82. Seneviratne J, Mandrekar J, Wijdicks EF, Rabinstein AA (2008) Predictors of extubation failure in myasthenic crisis. Arch Neurol 65:929-933

83. Vianello A, Bevilacqua M, Arcaro G, Gallan F, Serra E (2000) Noninvasive ventilatory approach to treatment of acute respiratory failure in neuromuscular disorders. A comparison with endotracheal intubation. Intensive Care Med 26:384-390

84. Wu JY, Kuo PH, Fan PC, Wu HD, Shih FY, Yang PC (2009) The role of non-invasive ventilation and factors predicting extubation outcome in myasthenic crisis. Neurocrit Care 10:35-42
85. Orlikowski D, Prigent H, Sharshar T, Lofaso F, Raphael JC (2004) Respiratory dysfunction in Guillain-Barré Syndrome. Neurocrit Care 1:415-422

86. Cheng BC, Chang WN, Chang CS, Tsai NW, Chang CJ, Hung PL, Wang KW, Chen JB, Tsai CY, Hsu KT, Chang HW, Lu CH (2004) Predictive factors and long-term outcome of respiratory failure after Guillain-Barré syndrome. Am J Med Sci 327:336-340

87. Carlucci A, Schreiber A, Mattei A, Malovini A, Bellinati J, Ceriana P, Gregoretti C (2013) The configuration of bi-level ventilator circuits may affect compensation for non-intentional leaks during volume-targeted ventilation. Intensive Care Med 39:59-65

88. Gifford AH (2014) Noninvasive ventilation as a palliative measure. Curr Opin Support Palliat Care 8:218-224

89. Boussaïd G, Lofaso F, Santos DB, Vaugier I, Pottier S, Prigent H, Orlikowski D, Bahrami S (2016) Factors influencing compliance with non-invasive ventilation at long-term in patients with myotonic dystrophy type 1: a prospective cohort. Neuromuscul Disord 26: 666-674

90. Luo F, Annane D, Orlikowski D, He L, Yang M, Zhou M, Liu GJ (2017) Invasive versus non-invasive ventilation for acute respiratory failure in neuromuscular disease and chest wall disorders. Cochrane Database Syst Rev 12:CD008380

91. Ricci G, Baldanzi S, Seidita F, Proietti C, Carlini F, Peviani S, Antonini G, Vianello A, Siciliano G, Italian GSD II group (2018) A mobile app for patients with Pompe disease and its possible clinical applications. Neuromuscul Disord 28:471-475

92. Trucco F, Pedemonte M, Racca F, Falsaperla R, Romano C, Wenzel A, D'Agostino A, Pistorio A, Tacchetti P, Bella C, Bruno C, Minetti C (2019) Tele-monitoring in paediatric and young home-ventilated neuromuscular patients: a multicentre case-control trial. J Telemed Telecare 25:414-424

Publisher's note Springer Nature remains neutral with regard to jurisdictional claims in published maps and institutional affiliations. 